\title{
Effect of internal recycling ratios on biomass parameters and simultaneous reduction of nitrogen and organic matter in a hybrid treatment system
}

\author{
Dinh Duc Nguyen ${ }^{\mathrm{a}, \mathrm{b}}$, Huu Hao Ngo ${ }^{\mathrm{c}}$, Yong Soo Yoon ${ }^{\mathrm{d}}$ \\ ${ }^{a}$ Ho Chi Minh City University of Natural Resources and Environment, Viet Nam \\ ${ }^{\mathrm{b}}$ Lotus Engineering Co., LTD, South Korea \\ ${ }^{\mathrm{c}}$ School of Civil and Environmental Engineering, Faculty of Engineering and Information \\ Technology, University of Technology Sydney, Broadway, NSW 2007, Australia. \\ ${ }^{d}$ Department of Chemical Engineering, Dankook University, 448-701, South Korea
}

\section{Highlights}

- A hybrid system was developed by combining 3 treatment methods.

- The system was successful in nutrient and organic removal without using any chemical additives.

- Internal recycling ratios affected biomass growth and system performance.

- Biomass production and sludge yield under different runs was determined.

- The highest removal efficiency was achieved at the internal recycling ratio of $400 \%$.

\begin{abstract}
A new large-scale pilot hybrid treatment system of $53 \mathrm{~m}^{3} /$ day was developed by combining 3 treatment methods: switched internal recycling flows to equalization tank (EQ); rotating hanging media bioreactor (RHMBR); and submerged flat sheet membrane bioreactor (SMBR). The system was operated for more than 16 months in a real-world municipal wastewater treatment plant, using different internal recycling ratios and observing/monitoring the results. This paper addresses not only the urgent problems of treating nutrient and organic pollutants in municipal wastewater, but also assesses characteristics of biomass production, sludge yield, and observed yield during the pilot operation. It also details design parameters used to achieve these assessed levels. Furthermore, the effects and correlations of the loading rates, activated sludge and biomass parameters, on different runs were also studied. The purpose of this was to identify the most suitable indicator for assessing the hybrid system's performance. Results strongly indicated that increasing the internal circulation rate greatly influenced the declining yield trend. The lowest biomass production $\left(P x_{\text {,bio }}\right)$ and sludge yields $\left(P X_{\text {,VSS }}\right.$ or $\left.P X_{\text {,TSS }}\right)$ were shown for conditions in run 3 , and run 4 , respectively. Overall the developed treatment system performed extremely well in biological terms for actual municipal wastewater treatment and resulted in high pollutant removal efficiencies, reduced sludge production at a reasonable cost. The hybrid system is a potential option for wastewater treatment, reuse and economy.
\end{abstract}




\section{Keywords}

Integrated hybrid system; Municipal wastewater; Internal recycling ratio; Biomass production; Sludge yield; Observed yield

\section{Introduction}

In recent years, biological wastewater treatment technologies using membranes (MBR) combined with biofilm support media have received special attention from many scientists worldwide. This is evident from the increased number of scientific research papers addressing this topic. Together with ongoing research, these technologies are increasingly being developed and widely applied in wastewater treatment systems in many countries, because they offer economic and technical advantages over conventional technology that is becoming obsolete (Cresson et al., 2006, Jou and Huang, 2003, Jurecska et al., 2013, Leiknes et al., 2006, Li et al., 2013, Martin and Nerenberg, 2012 and Tarjányi-Szikora et al., 2013), including the chemical treatment processes (Fan et al., 2009). This information indicates that, despite showing immense potential for its application in the present and future, the problem of excessive sludge generation persists. The optimal parameters/values in the application of membrane technology are still limited, especially by biomass, or sludge generation, which remains an unwanted technological byproduct of these systems. Consequently, more effective methods of biomass management must be optimized through ongoing research.

The disposal of excess/residual sludge biomass from waste water treatment plants (WWTPs) is a matter of major concern (Kabir et al., 2011, Low and Chase, 1999 and Semblante et al., 2014) and a very practical question, because it directly affects investment costs of sludge treatment processes such as sludge digester, sludge dewatering, etc. Several effective technologies currently minimize excess sludge production, namely: ultra-sonication (Khanal et al., 2007 and Pilli et al., 2011), thermal treatment (Razmjoo and Sefidari, 2011), chemical treatment (Liu, 2003), etc. Alternative uses for excess sludge from municipal WWTPs have also proved to be beneficial in reuse, such as fertilizer in agriculture, and improving fertility of barren/infertile soils. However, that potential has inherent risks because many sources contain heavy metals, organic chemicals, viruses, etc. (Clarke and Smith, 2011 and Harrison et al., 2006). In addition, people's need for clean water is continually increasing, and effluent wastewater quality requirements have become increasingly more stringent as a result. This also causes an increase in sludge waste (Low and Chase, 1999). Therefore, to reduce biomass produced from the WWTPs, designers and engineers should deploy a uniform solution from management, applied technology, and environmental engineering for real-world solutions. Implementing informed guidelines based on enlightened government policies is essential for successful wastewater sludge mitigation and treatment in the future. Thus, a solution is needed to reduce excess sludge production at the first source rather than seeking the technologies to mitigate it after the generation of unwanted by-products (Wang et al., 2009).

This investigation seeks to offer a better interpretation and evaluation of biomass production, sludge yield, observed yield, and the correlation between them, in a system that has been regarded as effective and flexible. Better understanding of such features of the process could also provide valuable information for optimizing the versatility and measurement conditions in sludge treatment unit designs, installation and operation. 
In this paper, instead of proposing a uniform solution, we develop a method of managing an integrated approach for handling excess sludge. This approach was effective in handling simultaneous nutrient and organic matter. We further evaluated the influence of the internal recycle ratios in reducing excess sludge production, subsequently minimizing sludge yield, and also their effects on overall process performance. In addition, methods of predicting and estimating the amount of sludge produced every day are based on the newly determined internal recycle ratios. This allows reliable performance to be achieved, and hopefully more widespread application of the methods described herein.

\section{Methods}

\subsection{Influent wastewater characteristics/components of influent wastewater}

The wastewater quality data of the pilot plant influent was collected from the collection sump of a municipal wastewater treatment plant (WWTP) of $110,000 \mathrm{~m}^{3} /$ day, with characteristics within the range (average) of 175-460 (281.90) $\mathrm{mg}$ SS/L, 166.73-222.32 (205.76) mg $\mathrm{BOD}_{5} / \mathrm{L}, 187.7-334.9$ (238.83) $\mathrm{mg} \mathrm{COD}_{\mathrm{Cr}} / \mathrm{L}, 30.83-63.08$ (41.16) $\mathrm{mg} \mathrm{T}-\mathrm{N} / \mathrm{L}, 0.00-1.06$

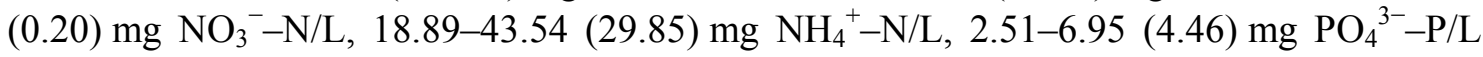
and 3.00-8.39 (5.45) $\mathrm{mg} \mathrm{T}-\mathrm{P} / \mathrm{L}$.

Influent wastewater $\mathrm{pH}$, Alkalinity (Alk.), and Coliform bacteria varied in a range of 7.0-8.0, 90-220, 1.5E +6-2.0E +7 , respectively, during the study period.

\subsection{Pilot plant and description}

A general process flow schematic of the hybrid treatment system is provided in Fig. 1. The pilot plant apparatus and experiments for municipal wastewater treatment were conducted using a high density polyethylene (HDPE) paneling, polyethylene sheet lining, and then installed in a WWTP in Y City, South Korea. It combined an innovative equalization tank which integrates anoxic/anaerobic conditions using fiber polypropylene carriers in one reactor, and an aerobic membrane bioreactor (MBR), along with a submerged flat sheet membrane for solid-liquid separation. The experimental pilot plant system had a capacity of approximately $53 \mathrm{~m}^{3} /$ day (Fig. 1). The size and working volume of each compartment are shown in Table 1. 


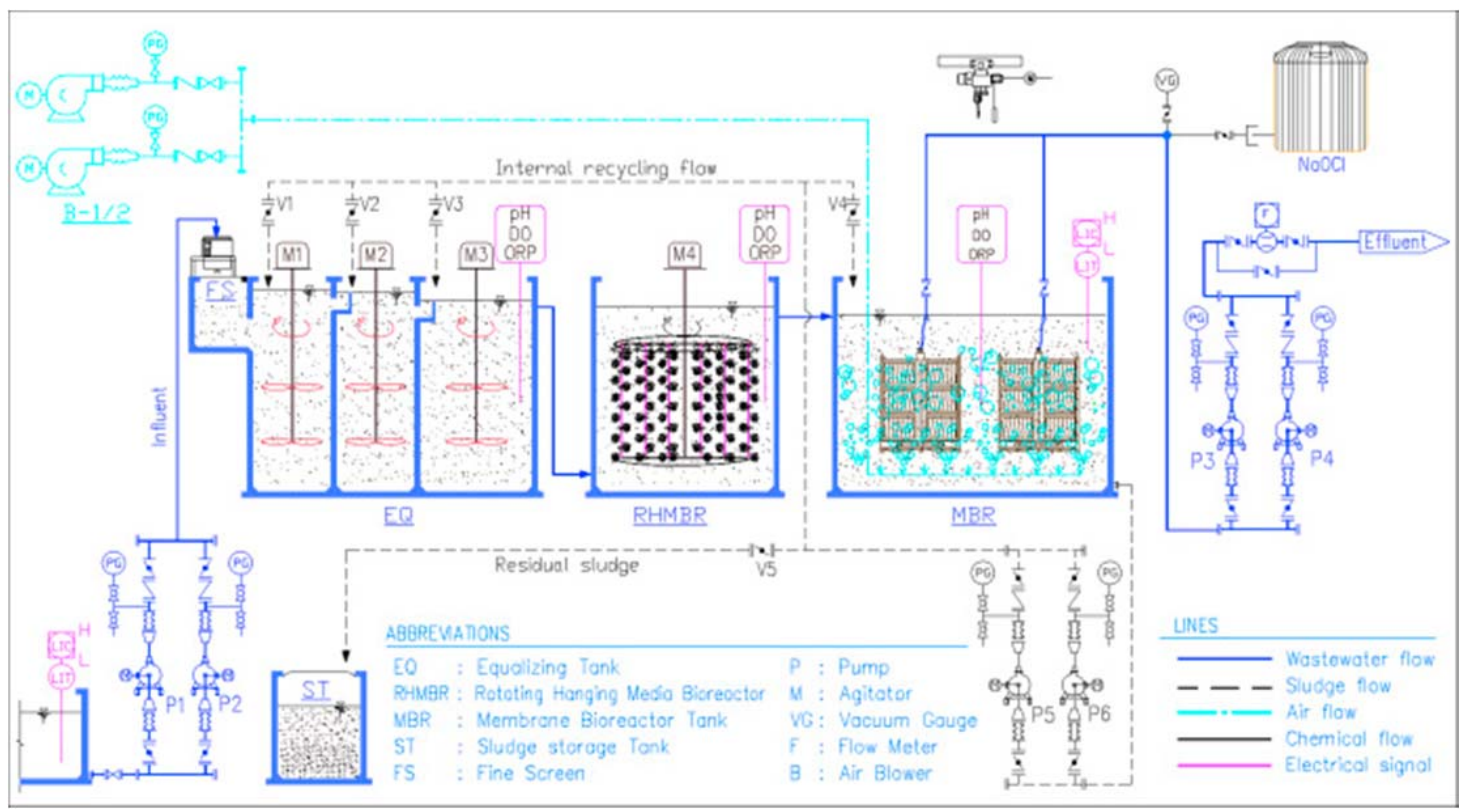

Fig. 1. Process flow of a new hybrid system.

Table 1. Size and working volumes of the reactors in the hybrid system.

\begin{tabular}{|c|c|c|c|c|c|}
\hline Parameters & Equalizing re & $\operatorname{actor}(\mathrm{EQ})$ & & RHMBR & MBR \\
\hline & EQ1 & EQ2 & EQ3 & & \\
\hline $\mathbf{W}>$ & $0.57 \times 1.0 \times 2.2$ & $0.57 \times 1.0 \times 2.2$ & $0.97 \times 1.0 \times 2.2$ & $2.2 \times 2.2 \times 2.2$ & $2.2 \times 2.2 \times 2.2$ \\
\hline WV (m3) & 1.226 & 1.197 & 1.989 & 9.922 & 9.438 \\
\hline
\end{tabular}

$W \times L \times H=$ Width $(\mathrm{m}) \times$ Length $(\mathrm{m}) \times$ Height $(\mathrm{m}) ; \mathrm{WV}=$ Working volume $\left(\mathrm{m}^{3}\right)$.

Raw wastewater from the municipal WWTP was successively pumped alternately by two automatic centrifugal pumps and passed through a fine screen (FS), with $5 \mathrm{~mm}$ openings, to the equalization tank (EQ). In the equalization tank, the concentration and flow of wastewater was balanced prior to the wastewater entering the anaerobic/anoxic tank (RHMBR) to initiate the denitrification process and alkalinity recovery. From there, a gravity assisted flow channeled the effluent to the membrane bioreactor (MBR) under aerobic conditions with high biomass concentration for carbonaceous removal and nitrification, before being pumped alternately through two automatic centrifugal suction pumps (P3, P4) into the environment. Additionally, an EQ and RHMBR equipped with agitators were provided in order to complete mixing the contents of biomass and pollutants. The RHMBR has a moving biofilm carrier serving as fiber polypropylene media.

Two automatic centrifugal suction pumps (P5, P6) were employed to maintain the internal recycle flows from the MBR to the EQ to prevent shock loading, carry out denitrification, reduce oxygen concentration in the internal recycle, partially remove phosphorus, and decomposition of excess sludge, and maintain the biomass concentration in the RHMBR. The internal recycle flows were adjusted based on amounts of activated sludge at rates ranging from 100 percent to 400 percent of the average daily flow, as well as the required discharging daily access biomass sludge amounts of $0.12-0.19 \mathrm{~m}^{3} /$ day in order to keep the MLSS as it was originally designed. 
The microfiltration membrane used in this study was a submersible flat sheet membrane, with a total surface area of $120 \mathrm{~m}^{2}$, and average pore size of $0.25 \mu \mathrm{m}$ (Yuasa Corporation, South Korea). Two automatic air blowers (Hwang Hae Electric Co., Ltd., South Korea) continuously injected compressed air into a coarse bubble diffuser located at the bottom of the MBR to maintain adequate DO, and to scrub the membrane surface to minimized membrane fouling. All the equipment, machinery and the system's operating mode were each set up in 2 modes of action, i.e. manual operation and automatic operation.

\subsection{Operating conditions}

The new hybrid treatment system was operated under real-world conditions. The detailed operating conditions of the system experiment were conducted using identical operating conditions described in another recent study (Nguyen et al., 2014b), and a few typical parameters are given in Table 2.

Table 2. Operating conditions and key experimental parameters of each run of pilot system.

\begin{tabular}{|c|c|c|c|c|}
\hline \multirow[t]{2}{*}{ Factors } & \multicolumn{4}{|c|}{ Internal recirculation rate $(R)$} \\
\hline & Run 1 & Run 2 & Run 3 & Run 4 \\
\hline Influent flow rate (m3/day) & $60.64 \pm 2.85$ & $57.67 \pm 5.70$ & $51.43 \pm 3.94$ & $52.44 \pm 5.08$ \\
\hline HRT in RHMBR (h) & $1.97 \pm 0.10$ & $1.39 \pm 0.15$ & $1.16 \pm 0.09$ & $0.92 \pm 0.08$ \\
\hline HRT in MBR (h) & $1.87 \pm 0.09$ & $1.32 \pm 0.15$ & $1.11 \pm 0.08$ & $0.87 \pm 0.08$ \\
\hline Mixed liquor in RHMBR (g/L) & $5.63 \pm 0.70$ & $6.84 \pm 0.63$ & $5.13 \pm 0.59$ & $5.53 \pm 0.38$ \\
\hline Mixed liquor in MBR (g/L) & $6.72 \pm 1.06$ & $7.72 \pm 0.51$ & $5.70 \pm 0.73$ & $6.16 \pm 0.45$ \\
\hline ORP in EQ3 (mV) & $-212.8 \pm 16.36$ & $-191.55 \pm 12.06$ & $-152.27 \pm 19.71$ & $-147.82 \pm 19.34$ \\
\hline ORP in RHMBR (mV) & $-307.2 \pm 7.02$ & $-314.55 \pm 10.4$ & $-323.02 \pm 20.89$ & $-330.42 \pm 14.76$ \\
\hline ORP in MBR (mV) & $114.2 \pm 10.38$ & $134.73 \pm 13.26$ & $175.67 \pm 17.12$ & $151.17 \pm 12.62$ \\
\hline Sludge age (days) & \multicolumn{4}{|c|}{$16.15-20.11(17.04)$} \\
\hline Permeate flow rate $\left(\mathrm{L} / \mathrm{m}^{2} h\right)$ & \multicolumn{4}{|c|}{$18.45-28.21(22.81)$} \\
\hline Operating pressure (kPa) & \multicolumn{4}{|l|}{$20.0-51.0$} \\
\hline Filtration cycle (min) & \multicolumn{4}{|c|}{$10 \min (9 \min$ filtration followed by a 1 min relax) } \\
\hline DO in RHMBR (mg/L) & \multicolumn{4}{|l|}{$\leq 0.05$} \\
\hline DO in $\operatorname{MBR}(\mathrm{mg} / \mathrm{L})$ & \multicolumn{4}{|c|}{$1.70-3.21(2.64 \pm 0.37)$} \\
\hline Membrane pore size $(\mu \mathrm{m})$ & \multicolumn{4}{|l|}{$0.1-0.4(0.25)$} \\
\hline Temperature $\left({ }^{\circ} \mathrm{C}\right)$ & \multicolumn{4}{|c|}{$10.0-24.9^{\circ} \mathrm{C}$ depending on the season in a year } \\
\hline SADm $\left(m^{3} \text { air } / h^{2}\right)^{2}$ & \multicolumn{4}{|c|}{$0.875-1.12$} \\
\hline SADp ( $\mathrm{m}^{3}$ air $/ \mathrm{m}^{3}$ permeate $)$ & \multicolumn{4}{|l|}{$38.360-49.101$} \\
\hline Chemical cleaning reagent & \multicolumn{4}{|c|}{$\mathrm{NaOCl}$ solution $0.5-1.2 \%$} \\
\hline
\end{tabular}

SADm: Specific aeration demand per unit membrane area. SADp: Specific aeration demand per unit permeate flux. Aver. \pm STD: Average \pm Standard deviation.

\subsection{Analytical methods}

For a comprehensive approach to evaluating the stability of the hybrid system during operation, both typical parameters and sampling protocols were followed, with supervisory control and analysis oversight. The samples were collected at the influent, effluent (permeate stream) and at each reactor, with a sampling frequency of two to three times per week, in order to measure the following: biological oxygen demand $\left(\mathrm{BOD}_{5}\right)$, chemical oxygen demand $\left(\mathrm{COD}_{\mathrm{Cr}}\right)$, total coliform bacteria, mixed liquor suspended solids (MLSS), total suspended solids (TSS), mixed liquor volatile suspended solids (MLVSS), alkalinity, total nitrogen (T$\mathrm{N}$ ), ammonia nitrogen $\left(\mathrm{NH}_{4}{ }^{+}-\mathrm{N}\right)$, total phosphorus (T-P), and coliforms. All samples were 
processed following the protocols/standard methods for the sampling, preservation, storage and analysis as described in detail elsewhere (Nguyen et al., 2014b).

The daily biomass production, $P x_{\text {,bio }}(\mathrm{kg}$ VSS/day); net waste activated sludge produced, $P X_{\text {,VSS }}\left(\mathrm{kg} \mathrm{VSS} /\right.$ day); solids production, $\mathrm{P}_{\mathrm{X}, \mathrm{TSS}}$ (kg TSS/day); and observed growth yield based on TSS and VSS, $Y_{\text {obs }}\left(\mathrm{kg} \mathrm{VSS} / \mathrm{kg} \mathrm{COD}_{\mathrm{Cr}}\right.$ or $\left.\mathrm{kg} \mathrm{TSS} / \mathrm{kg} \mathrm{COD}_{\mathrm{Cr}}\right)$ was computed/calculated based on the data derived from the sample analysis (Metcalf et al., 2004).

Influent and effluent samples were regularly screened for coliforms and their numbers determined. The DO concentration, $\mathrm{pH}$ values, oxidation reduction potentials (ORPs), and temperature were determined online using XL60 (Thermo Fisher Scientific Inc., US) and YSI 550A (YSI Environmental, US), respectively.

\section{Results and discussion}

\subsection{Overall system performance}

A new hybrid RHMBR and MBR system using polypropylene fiber media and a submerged plate membrane bioreactor, performed excellently in removing $\mathrm{COD}, \mathrm{NH}_{4}{ }^{+}-\mathrm{N}, \mathrm{T}-\mathrm{N}$ and $\mathrm{T}-\mathrm{P}$, under different operating conditions, i.e. under different internal recycling ratios (Fig. 2). The high removal efficiencies were comparable to those reported in other studies using more complex reactors and processes, and/or more expensive bio-film media. It suggests that this system not only has a high removal efficiency, but also is much more cost-effective (Nguyen et al., 2014a) than previously explored systems.
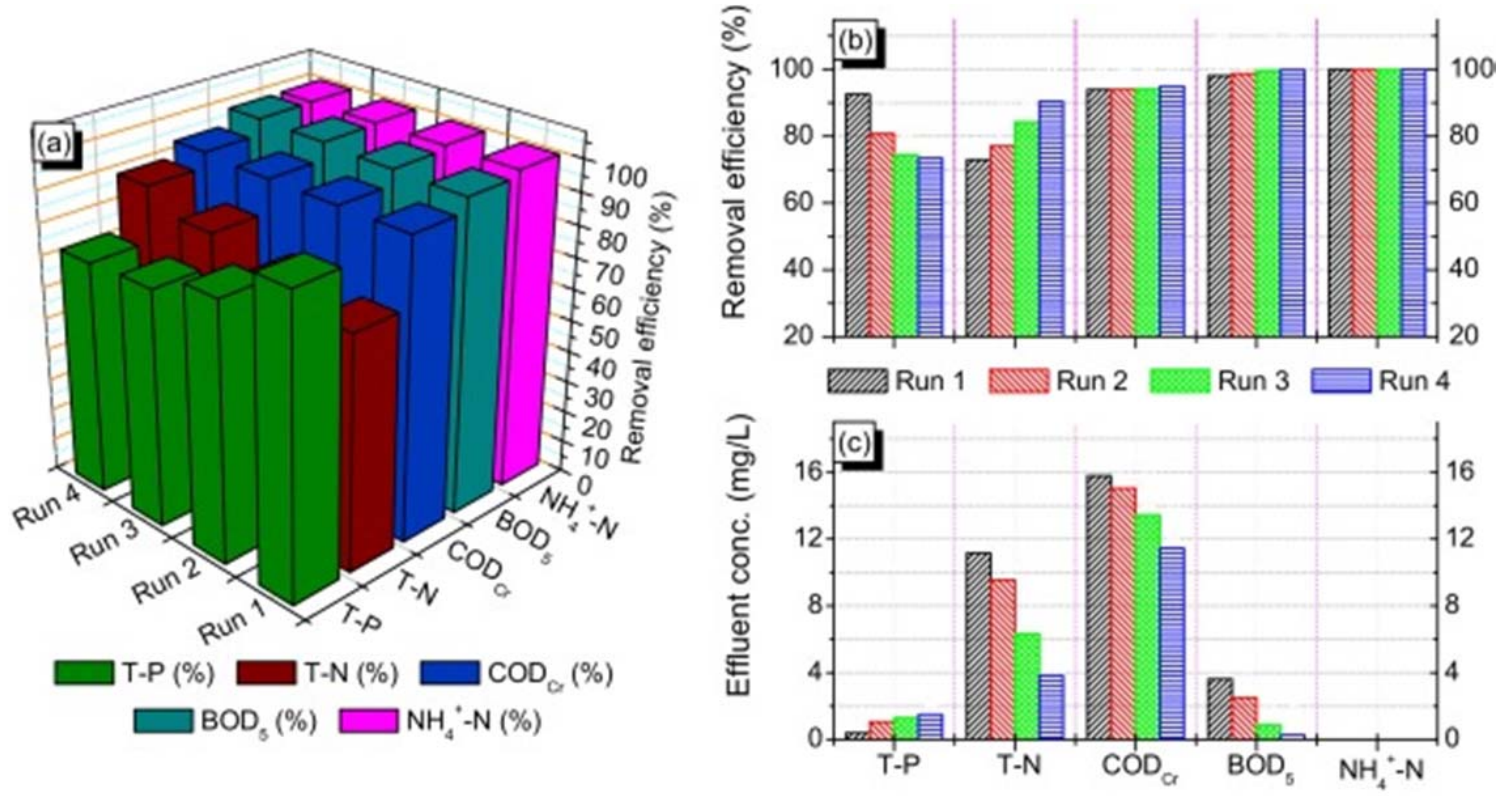

Fig. 2. Overall performance of the hybrid system at different internal recycling ratios.

As observed from the data, the internal recycling ratio significantly influenced the efficiency in removing nitrogen with an increase in the internal recycle ratio $(R)$, thereby substantially improving the nitrogen removal efficiency. 
T-N concentration in the final effluent mainly took the form of $\mathrm{NO}_{3}{ }^{-}-\mathrm{N}$ due to the system design specification, and $\mathrm{NO}_{3}{ }^{-}-\mathrm{N}$ concentration in effluent was dependent on the internal recycle ratio $(R)$. Specifically, for run 1 , run 2 , run 3 and run 4 , the respective $\mathrm{NO}_{3}{ }^{-}-\mathrm{N}$ effluents were $9.61 \pm 1.27 \mathrm{mg} / \mathrm{L}, 8.18 \pm 0.86 \mathrm{mg} / \mathrm{L}, 5.1 \pm 1.33 \mathrm{mg} / \mathrm{L}$ and $3.4 \pm 0.74 \mathrm{mg} / \mathrm{L}$.

Like $\mathrm{T}-\mathrm{N}$, it was also found that increasing internal recycling ratio could improve the $\mathrm{COD}_{\mathrm{Cr}}$ and $\mathrm{BOD}_{5}$ removal efficiencies, while conversely, the TP removal efficiencies were decreased. Overall, during the entire period of operation, results revealed that the removal efficiencies of $\mathrm{T}-\mathrm{N}, \mathrm{COD}_{\mathrm{Cr}}$ and $\mathrm{BOD}_{5}$ were very high, despite the significant fluctuation in influent flow, and, equally important, results acquired also indicated that run 4 achieved significantly greater $\mathrm{T}-\mathrm{N}, \mathrm{COD}_{\mathrm{Cr}}$ and $\mathrm{BOD}_{5}$ removal rates over other runs (run 1 , run 2 , and run 3) (Fig. 2).

However, the hybrid pilot study results proved the system was highly efficient and always maintained a stable level in each run, despite a significant fluctuation in the influent flow qualities. It also fitted well with the predicted values, suggesting it is a useful method for determining the internal recycling ratio for a specific simultaneous nutrient and organic pollutant concentration requirement for effluent. Furthermore, the results show that balancing the energy costs and discharging/effluent water quality requirements of each locality's needs for sight-specific use, can be adjusted through the internal recirculation rate.

In this experimental study, the hybrid pilot system achieved complete nitrification as expressed through the final effluent $\mathrm{NH}_{4}{ }^{+}-\mathrm{N}$ concentrations which were nil. The results demonstrate that the nitrification process in this system occurred completely with all $\mathrm{NH}_{4}{ }^{+}-\mathrm{N}$ converted into nitrate nitrogen (Nguyen et al., 2014b).

The long-term experimental results of the integrated hybrid pilot system demonstrated how to incorporate enhanced biological contaminants removal, along with significantly diminished membrane fouling at a constant flux, and that specific energy consumption can be effectively reduced (Nguyen et al., 2014a).

In addition to evaluating the overall performance of the system under different runs and monitoring the removal efficiencies of organic matter and nutrients, the experiment also evaluated the daily biomass production, sludge yield, observed yield and correlations between the biomass growth parameters. These aspects of the experiment are described in more detail below.

\subsection{Variations of biomass production under different runs}

The major component of biomass is organic matter (Metcalf et al., 2004); the influent and effluent ratio of $\mathrm{BOD}_{5} / \mathrm{COD}_{\mathrm{Cr}}$ was $0.86 \pm 0.096$ and $0.09 \pm 0.093$, respectively, during the entire period of the experiment. These indicated that the major component in wastewater is mostly organic matter. Consequently, the representative parameter to evaluate biomass production in the reactors was expressed through volatile suspended solid (VSS).

For evaluation and determination of daily biomass production, $P x_{\text {,bio, }}$, in a hybrid system under different operating conditions, the amount present is determined on the basis of balance cell growth and decay. The following equations, Eqs. (1) and (2), (Metcalf et al., 2004), are used in conjunction with information presented in Table 3. 


$$
\begin{aligned}
S=\frac{K_{S}\left[1+\left(k_{d}\right) \mathrm{SRT}\right]}{\left(Y_{k}-k_{d}\right) \mathrm{SRT}-1} & \\
P_{x, \text { bio }}= & \frac{Q Y\left(S_{0}-S\right)\left(1 \mathrm{~kg} / 10^{3} \mathrm{~g}\right)}{1+\left(k_{d}\right) \mathrm{SRT}} \\
& +\frac{\left(f_{d}\right)\left(k_{d}\right) Q Y\left(S_{0}-S\right) \mathrm{SRT}\left(1 \mathrm{~kg} / 10^{3} \mathrm{~g}\right)}{1+\left(k_{d}\right) \mathrm{SRT}} \\
& +\frac{Q Y_{n}\left(\mathrm{NO}_{x}\right)\left(1 \mathrm{~kg} / 10^{3} \mathrm{~g}\right)}{1+\left(k_{d n}\right) \mathrm{SRT}}
\end{aligned}
$$

where $P_{x, \text { bio }}$ : rate of biomass production as VSS wasted, (g/day); $Q$ : influent wastewater flowrate, ( $\mathrm{m}^{3} /$ day); SRT: solids retention time, (day); $K_{s}$ : half-velocity constant, $(\mathrm{mg} / \mathrm{L}) ; Y$ : biomass yield for heterotrophs, ( $\mathrm{g} \mathrm{VSS} / \mathrm{g}$ bCOD); $Y_{n}$ : biomass yield for nitrification, ( $\mathrm{g}$ $\mathrm{VSS} / \mathrm{g} \mathrm{NH} \mathrm{NH}_{4} \mathrm{~N}$ ); $S_{0}$ : influent substrate concentration, (mg/L); $S$ : effluent dissolved substrate concentration, $(\mathrm{mg} / \mathrm{L})$; $\mathrm{NOx}$ : concentration of $\mathrm{NH}_{4}-\mathrm{N}$ in the influent flow that is nitrified,

\begin{tabular}{|c|c|c|c|c|c|}
\hline \multicolumn{3}{|c|}{ Carbonaceous material } & \multicolumn{3}{|c|}{ Nitrification kinetics } \\
\hline Parameter & Value & Unit & Parameter & Value & Unit \\
\hline $\mathrm{K}_{\mathrm{s}}, 12^{\circ} \mathrm{C}$ & 20.000 & $\mathrm{~g} \mathrm{bCOD} / \mathrm{m} 3$ & $\mathrm{~K}_{\mathrm{n}}, 12^{\circ} \mathrm{C}$ & 0.634 & $\mathrm{~g} \mathrm{NH} 4-\mathrm{N} / \mathrm{m} 3$ \\
\hline $\mathrm{k}_{\mathrm{d}}, 12^{\circ} \mathrm{C}$ & 0.107 & g VSS/g VSSday & $\mathrm{k}_{\mathrm{dn}}, 12^{\circ} \mathrm{C}$ & 0.107 & g VSS/g VSS day \\
\hline $\mathbf{Y}$ & 0.400 & g VSS/g bCOD & $Y_{\mathbf{n}}$ & 0.150 & g VSS/g NH4-N \\
\hline$\mu \mathrm{m}, 12^{\circ} \mathrm{C}$ & 4.898 & g VSS/gVSSday & $\mu \mathbf{n}, \mathbf{m}, 12^{\circ} \mathrm{C}$ & 0.612 & g VSS/g VSS day \\
\hline fd & 0.150 & Unit less & $\mu \mathrm{n}, 12^{\circ} \mathrm{C}$ & 0.109 & g VSS/g VSS day \\
\hline
\end{tabular}
$(\mathrm{mg} / \mathrm{L}) ; \mathrm{k}_{d n}$ : endogenous decay coefficient for nitrifying organisms, (g VSS/g VSS. day); $k_{d}$ : endogenous decay coefficient, (g VSS/g VSS. day)

Table 3. Biological kinetic constants.

On the basis of the variables, the parameters were analyzed and other information is presented in Table 3 . The variations in daily biomass production during the entire operational period of 475 days are plotted in Fig. 3a. In order to quantify the significance of these results the average biomass production in each run was also calculated, as illustrated in Fig. 3b. They show the average of biomass production and standard deviation for the hybrid system during runs $1,2,3$ and 4 . They amounted to $2.91 \pm 0.31 \mathrm{~kg} \mathrm{VSS} /$ day, $2.78 \pm 0.44 \mathrm{~kg} \mathrm{VSS} /$ day, $2.19 \pm 0.33 \mathrm{~kg} \mathrm{VSS} /$ day, and $2.22 \pm 0.32 \mathrm{~kg} \mathrm{VSS} /$ day, respectively. Meanwhile, the excess sludge production discharged daily from the MBR tank ranged from 120 to $180 \mathrm{~L}$, in order to ensure a moderate level of biomass concentration in the RHMBR and MBR. These values 
ranged between 3.33 and $6.949 \mathrm{~g}$ MLVSS/L (4.155 to $7.810 \mathrm{~g} \mathrm{MLSS} / \mathrm{L}$ ) and between 3.33 and 6.949 g MLVSS/L (4.565 to 8.690 g MLSS/L), respectively.

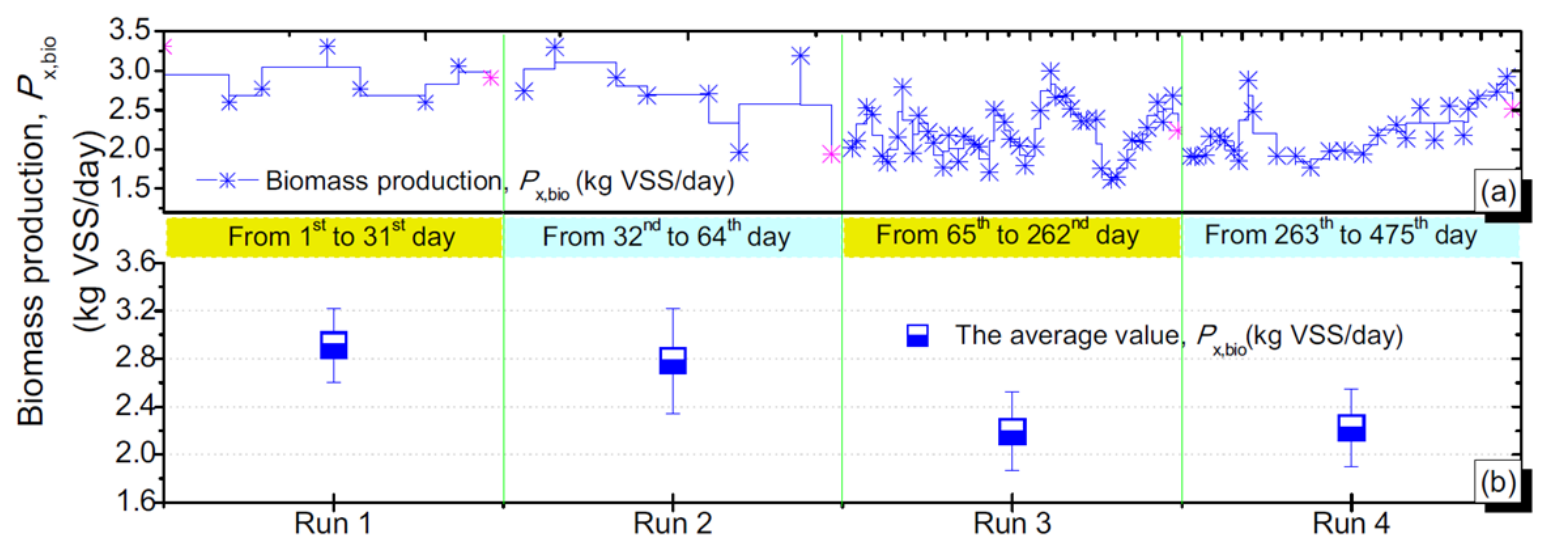

Fig. 3. Variation of biomass production (a) and the average, with standard deviation, in each run period (b).

As results illustrated in Fig. 3 reveal, in order to achieve the minimum and maximum biomass production, the system should be operated in run 3 and run 1, respectively, on the basis of changes in internal recycling flow rates. Therefore, the hybrid system can minimize and reduce the sludge production in a run 3.

As the results presented in Fig. $3 \mathrm{~b}$ indicate, the increasing recycling ratio tends to reduce the sludge production, and achieve optimal peak value of sludge production in run 3, when reversals exhibited a slight upward trend during the experimental period of run 4 . Hence, less or more internal recycle flow will affect the optimal sludge production of the system. Overall, the experiment as designed, consisting of four runs, confirmed the influence of the internal recycling ratio on the biomass production of the process.

\subsection{Variations of sludge yield under different runs}

Basically, excess sludge yield is an important economic factor because it needs to be treated before being discharged into the environment, or used for specific purposes. Its treatment may account for a large percentage of the system's total operating costs (Wang et al., 2009).

In this study, the daily sludge and solids production, calculated using the database, was analyzed according to the following equations (Metcalf et al., 2004):

$$
\begin{aligned}
& P_{x, \mathrm{VSS}}=P_{x, \text { bio }}+Q(\mathrm{nbVSS})\left(\frac{1 \mathrm{~kg}}{10^{3} \mathrm{~g}}\right) \\
& P_{x, \mathrm{TSS}}=\frac{P_{x, \text { bio }}}{0.85}+Q(\mathrm{nbVSS})\left(\frac{1 \mathrm{~kg}}{10^{3} \mathrm{~g}}\right)+Q\left(\mathrm{TSS}_{o}-\mathrm{VSS}_{o}\right)
\end{aligned}
$$

where $P X_{\text {,VSS }}$ : net waste activated sludge produced each day, (kg VSS/day); $P X_{\text {,TSs: }}$ solids production in terms of TSS, (kg TSS/day); nbVSS: non-biodegradable VSS in the influent wastewater, $\left(\mathrm{g} / \mathrm{m}^{3}\right)$; NOx: concentration of $\mathrm{NH}_{4}-\mathrm{N}$ in the influent flow that is nitrified, $(\mathrm{mg} / \mathrm{L})$; and other terms as defined above. 
The production of sludge through biodegradation in an MBR can, in principle, be reduced to zero by controlling sludge retention time (SRT). The change in SRT has by far the greatest impact on sludge production (Judd Simon and Claire, 2011). However, increased sludge retention time affected the quality of treated wastewater, namely T-P.

Fig. 4 presents the average with standard deviation (b and d) and the variations (a and c) of daily sludge yield during each run and during operation. The solids data points presented in Fig. 4 were normalized by the total amount of $\mathrm{COD}_{\mathrm{Cr}}$ entering the hybrid system each day. Results presented in Figs. $4 \mathrm{~b}$ and d show the average sludge yield based on VSS and TSS were estimated; these are summarized in Table 4. It is evident that sludge yield decreased in the system depending on internal recycling ratios (runs), meaning that the sludge yield in the reactor decreased as the internal recycling ratio increased. This achieved a maximum and minimum value at a first run and last run, corresponding to a sludge yield of $9.52 \mathrm{~kg} T S S /$ day and $7.05 \mathrm{~kg}$ TSS/day, respectively. However, on the basis of results presented in Fig. 4, and characteristics of the influent wastewater and mixed liquor data, it is possible to estimate a biomass yield based on VSS or TSS in the system during changed $\mathrm{COD}_{\mathrm{Cr}}$ loading rates.

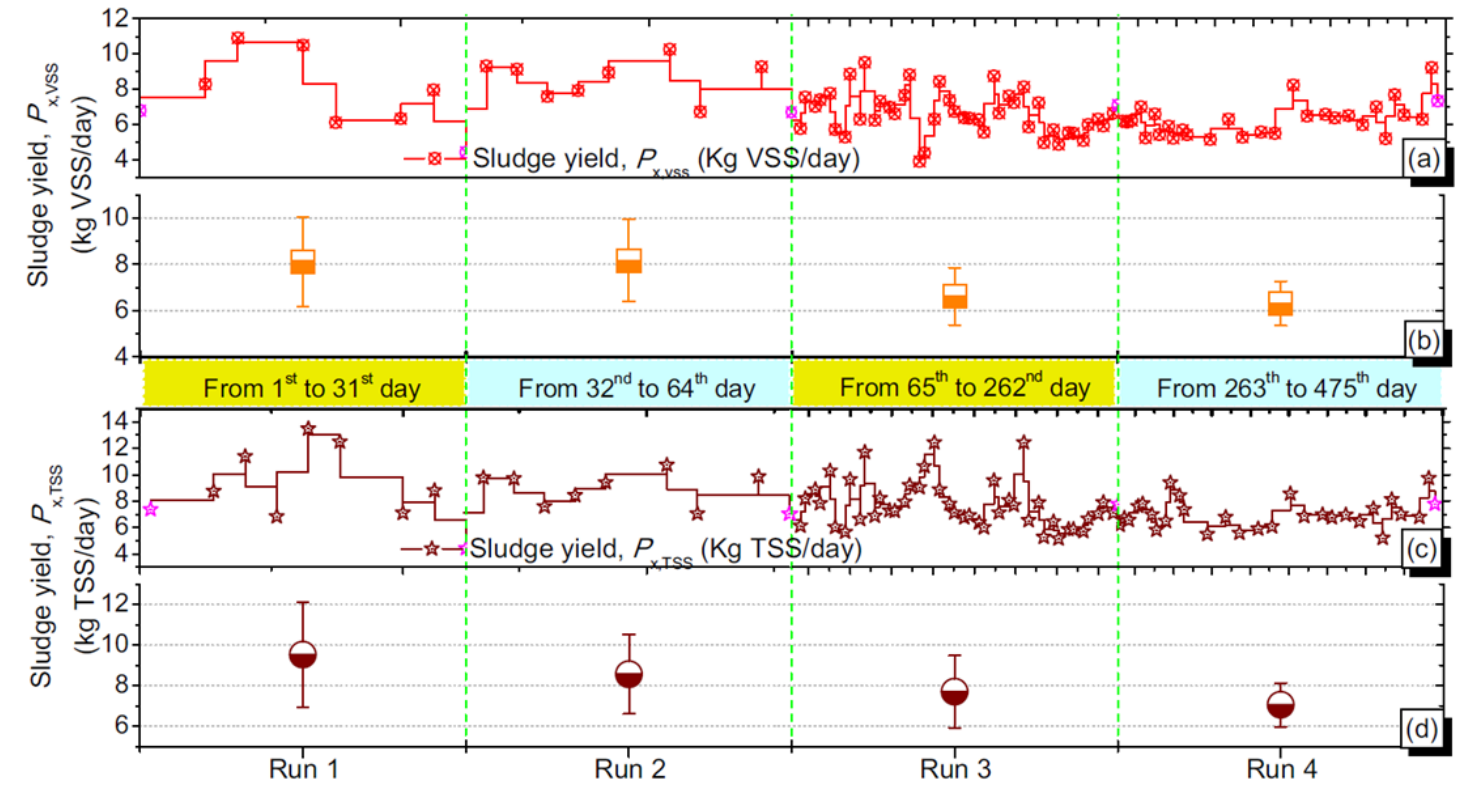

Fig. 4. Average with standard deviation (a) and (c) and the variations (b) and (d) of daily sludge yield during each runs.

Thus, this research demonstrated that the hybrid system can indeed perform the dual purpose of sludge reduction and improve the quality of treated wastewater including the removals of nutrient, organic and SS (Nguyen et al., 2014a, Nguyen et al., 2014b and Phan et al., 2014). 
Table 4. Summary of sludge yield during each run based on VSS and TSS.

\begin{tabular}{lllll}
\hline Duration (days) & Run & Internal recirculation ratio & Sludge yield & \\
\hline & & & $\mathrm{kg} \mathrm{VSS} /$ day & $\mathrm{kg} \mathrm{TSS} /$ day \\
$\mathbf{1 - 3 0}$ & 1 & $1 \mathrm{Q}$ & $6.11-10.90$ & $6.82-13.48$ \\
& & & $(8.12 \pm 1.93)$ & $(9.52 \pm 2.59)$ \\
$\mathbf{3 1 - 6 3}$ & 2 & $2 \mathrm{Q}$ & $4.42-10.26$ & $4.42-10.74$ \\
& & & $(8.17 \pm 1.77)$ & $(8.55 \pm 1.95)$ \\
$\mathbf{6 4 - 2 6 1}$ & 3 & $3 \mathrm{Q}$ & $3.89-9.52$ & $5.15-12.44$ \\
& & & $(6.61 \pm 1.24)$ & $(7.70 \pm 1.79)$ \\
$\mathbf{2 6 2 - 4 7 0}$ & 4 & $4 Q$ & $5.15-9.23$ & $5.19-9.74$ \\
& & & $(6.31 \pm 0.96)$ & $(7.05 \pm 1.09)$ \\
\hline
\end{tabular}

The average values and standard deviation are shown in parentheses.

\subsection{Variations of observed sludge yield under different runs}

The indicated observed biomass yield is based on the actual measurements of biomass production and substrate consumption (Metcalf et al., 2004).

The observed yield, $Y_{\text {obs }}$ is based on the amount of solids production measured relative to the substrate removal, and is calculated in terms of $\mathrm{g} \mathrm{TSS} / \mathrm{g}$ COD or $\mathrm{g} \mathrm{BOD}$, or relative to VSS as $\mathrm{g}$ VSS/g COD or g BOD. It decreases as the sludge retention time (SRT) increases due to biomass loss caused by more endogenous respiration (Metcalf et al., 2004).

The observed yield, $Y_{\text {obs }}$, of the hybrid system under different run conditions, was calculated based on the previous date of: first, activated sludge produced $\left(P_{\mathrm{X}, \mathrm{VSS}}\right)$; and second, solids production $\left(P_{\mathrm{X}, \mathrm{TSS}}\right)$. This was according to the following equation (Metcalf et al., 2004):

$Y_{\mathrm{obs}}=\frac{Y}{1+\left(k_{d}\right) \mathrm{SRT}}+\frac{\left(f_{d}\right)\left(k_{d}\right)(Y) \mathrm{SRT}}{1+\left(k_{d}\right) \mathrm{SRT}}+\frac{X_{o, i}}{S_{0}-S}$

where $Y_{\text {obs }}: \mathrm{g}$ VSS/g substrate removed; Xo,i: nbVSS concentration in influent, $\left(\mathrm{g} / \mathrm{m}^{3}\right) ; f d$ : fraction of biomass that remains as cell debris, (g VSS/g VSS); $k d$ : endogenous decay coefficient, (g VSS/g VSS day); and other terms as defined above.

Experiment results revealed that increases in the following - organic loading rate, range of $0.46-0.95 \mathrm{~kg} \mathrm{COD} \mathrm{Cr}_{\mathrm{r}} / \mathrm{m}^{3}$ day, and observed yield of $Y_{\mathrm{obs}}-$ tended to diminish progressively. The influence of organic loading rate became evident in runs 2, 3 and particularly in run 4.

On the other hand, these results strongly indicate that increasing the internal circulation rate greatly influenced the declining observed yield trend. It means that the sludge yield cannot be degraded by simple aerobic digestion alone. Therefore, coupling of aerobic conditions and anaerobic/anoxic conditions in one system may not only provide the best conditions for nutrient removal (Lai et al., 2011, Nguyen et al., 2014a and Nguyen et al., 2014b), but also 
minimize excess sludge generation and optimize the hybrid system's operational performance.

According to Eq. (5), the average observed sludge yield data, with standard deviation under different runs, was plotted against the operating time data for the hybrid system's observed sludge yield as shown in Fig. 5. The range and average observed sludge based on VSS and TSS in the hybrid system during runs 1, 2, 3 and 4 are listed in Table 5. It also shows the variation of observed yield during operation inserted in Fig. 5a and c. This indicates that a much lower sludge yield in run 4 resulted from further degradation of organic materials that could be degraded via internal circulation flow to the RHMBR in anoxic/anaerobic conditions. Furthermore the observed biomass yield is usually less than the synthesis yield, because a portion of the substrate enters the cell mass to synthesize energy, in order to maintain growth and create new cells (Metcalf et al., 2004).

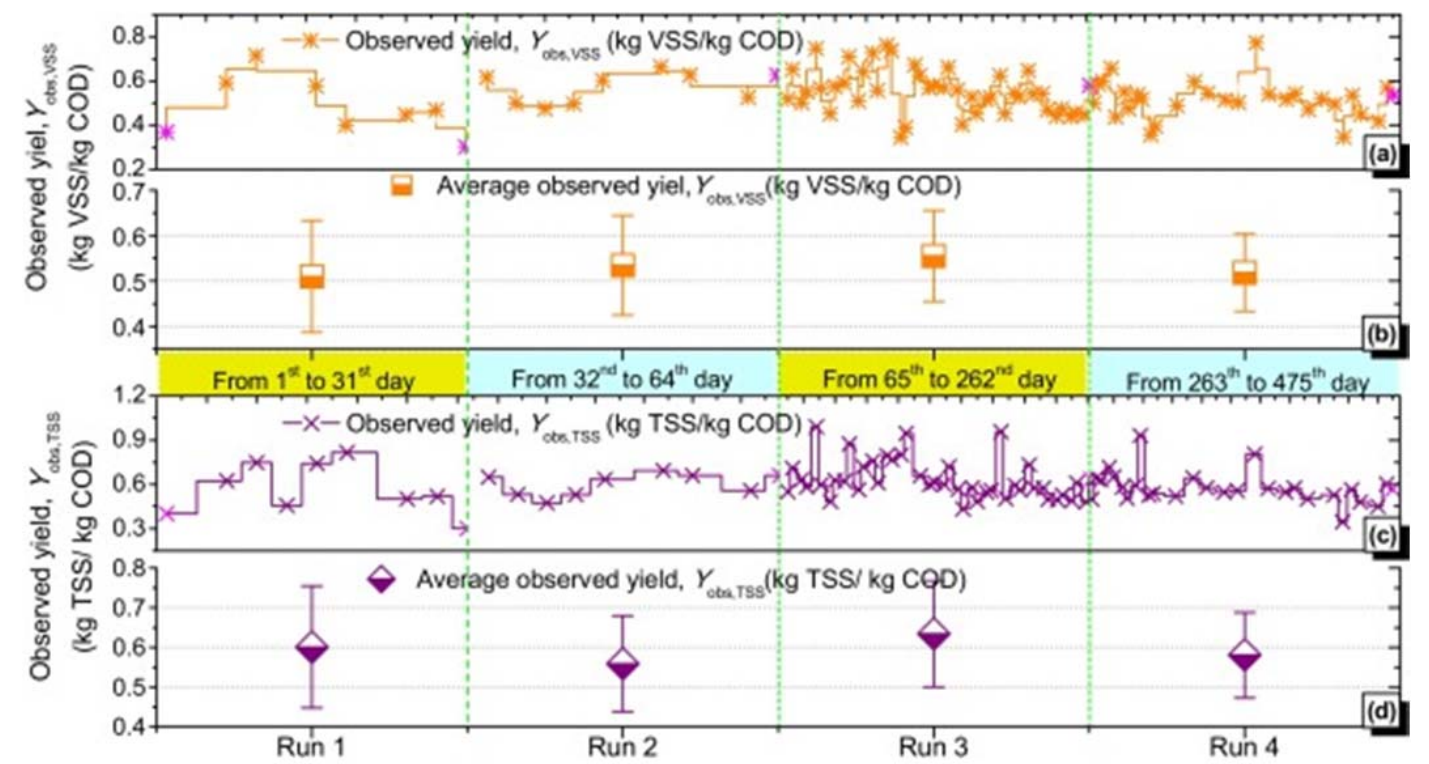

Fig. 5. Average with standard deviation (a) and (c) and the variations (b) and (d) of observed yield during each runs.

Table 5. Summary of observed yield during each run based on VSS and TSS.

\begin{tabular}{|c|c|c|c|c|}
\hline \multirow{2}{*}{ Duration (days) } & \multirow{2}{*}{ Runs } & \multirow{2}{*}{ Internal recirculation ratio } & \multicolumn{2}{|c|}{ Observed yield, $Y_{\text {obs }}$} \\
\hline & & & $\mathrm{kg} \mathrm{VSS} / \mathrm{kg} \mathrm{COD} \mathrm{Cr}_{\mathrm{r}}$ & $\mathrm{kg}$ TSS/kg COD $\mathrm{Cr}$ \\
\hline $1-31$ & 1 & $1 \mathrm{Q}$ & $\begin{array}{c}0.37-0.72 \\
(0.51 \pm 0.12)\end{array}$ & $\begin{array}{c}0.40-0.82 \\
(0.60 \pm 0.15)\end{array}$ \\
\hline $32-64$ & 2 & $2 \mathrm{Q}$ & $\begin{array}{c}0.30-0.66 \\
(0.53 \pm 0.11)\end{array}$ & $\begin{array}{c}0.30-0.69 \\
(0.56 \pm 0.12)\end{array}$ \\
\hline $65-262$ & 3 & $3 \mathrm{Q}$ & $\begin{array}{c}0.35-0.76 \\
(0.56 \pm 0.10)\end{array}$ & $\begin{array}{c}0.43-0.99 \\
(0.63 \pm 0.13)\end{array}$ \\
\hline $263-475$ & 4 & $4 \mathrm{Q}$ & $\begin{array}{c}0.35-0.77 \\
(0.52 \pm 0.09)\end{array}$ & $\begin{array}{c}0.35-0.93 \\
(0.58 \pm 0.11)\end{array}$ \\
\hline
\end{tabular}

The average values and standard deviation are shown in parentheses. 
All the above data demonstrates conditions that favored the performance of the hybrid system and its pre-fermentation process. In turn, this achieved better final effluent quality with respect to the discharge criteria, while achieving little variation in sludge yield in different runs.

\section{Conclusions}

Results from this hybrid treatment plant pilot study of the most efficient municipal wastewater treatment methods should provide some of the necessary data for creating a more versatile and efficient wastewater treatment plant, in terms of design, installation, and operation. It also creates the opportunity to achieve the sought-after goal of economical water reuse. Interestingly, the treatment efficiency of the hybrid system remained at a significantly high level throughout the course of this study.

Furthermore, increasing the internal recycling ratios will increase the simultaneous removal of nutrient (T-P, T-N) and organic (COD, BOD). In the meantime it will decrease the system's sludge production despite large variations (obvious fluctuations) in the influent qualities.

These results demonstrated the flexibility and robustness of a hybrid system, using three stages of the three types of integrated technologies available. They provide an optimum configuration which achieved highly efficient pollutant removal from municipal wastewater in both runs, along with significantly diminished sludge production.

\section{References}

Clarke, B.O., Smith, S.R., 2011. Review of 'emerging' organic contaminants inbiosolids and assessment of international research priorities for the agriculturaluse of biosolids. Environ. Int. 37 (1), 226-247.

Cresson, R., Carrère, H., Delgenès, J.P., Bernet, N., 2006. Biofilm formation during thestartup period of an anaerobic biofilm reactor-impact of nutrient complemen-tation. Biochem. Eng. J. 30 (1), 55-62.

Fan, J., Tao, T., Zhang, J., You, G.-1., 2009. Performance evaluation of a modified anaerobic/anoxic/oxic (A2/O) process treating low strength wastewater. Desalination 249 (2), 822 827.

Harrison, E.Z., Oakes, S.R., Hysell, M., Hay, A., 2006. Organic chemicals in sewagesludges. Sci. Total Environ. 367 (2), 481-497.

Jou, C.-J.G., Huang, G.-C., 2003. A pilot study for oil refinery wastewater treatmentusing a fixed-film bioreactor. Adv. Environ. Res. 7 (2), 463-469.

Judd Simon, Claire, J., 2011. The MBR Book: Principles and Applications of MembraneBioreactors for Water and Wastewater Treatment, second ed. Elsevier, Oxford,UK, pp. 536.

Jurecska, L., Barkács, K., Kiss, É., Gyulai, G., Felföldi, T., Tör"o, B., Kovács, R., Záray, G.,2013. Intensification of wastewater treatment with polymer fiber-based biofilmcarriers. Microchem. J. 107 (0), 108-114. 
Kabir, Mahmudul, Suzuki, Masafumi, Yoshimura, Noboru, 2011. Excess SludgeReduction in Waste Water Treatment Plants, Waste Water - Treatmentand Reutilization. In: Einschlag, F.S.G. (Ed.). InTech, ISBN 978-953-307-249-4, Available from: http://www.intechopen.com/books/waste-watertreatment-and-reutilization/excess-sludgereduction-in-waste-water-treatment-plants.

Khanal, S.K., Grewell, D., Sung, S., Van Leeuwen, J., 2007. Ultrasound applications in wastewater sludge pretreatment: a review. Crit. Rev. Environ. Sci. Technol. 37(4), 277-313.

Lai, T.M., Dang, H.V., Nguyen, D.D., Yim, S., Hur, J., 2011. Wastewater treatment usinga modified A2O process based on fiber polypropylene media. J. Environ. Sci.Health, A: Environ. Sci. Eng. 46 (10), 1068-1074.

Leiknes, T., Bolt, H., Engmann, M., Ødegaard, H., 2006. Assessment of membrane reactor design in the performance of a hybrid biofilm membrane bioreactor (BF-MBR). Desalination 199 (1), 328-330.

Li, C., Li, Y., Cheng, X., Feng, L., Xi, C., Zhang, Y., 2013. Immobilization of Rhodococcusrhodochrous BX2 (an acetonitrile-degrading bacterium) with biofilm-forming bacteria for wastewater treatment. Bioresour. Technol. 131 (0), 390-396.

Liu, Y., 2003. Chemically reduced excess sludge production in the activated sludge process. Chemosphere 50 (1), 1-7.

Low, E.W., Chase, H.A., 1999. Reducing production of excess biomass during waste-water treatment. Water Res. 33 (5), 1119-1132.

Martin, K.J., Nerenberg, R., 2012. The membrane biofilm reactor (MBfR) for water and wastewater treatment: principles, applications, and recent developments.Bioresour. Technol. $122(0), 83-94$.

Metcalf, L., Eddy, H., Tchobanoglous, G., 2004. Wastewater Engineering: Treatmentand Reuse. Metcalf \& Eddy, Inc., McGraw-Hill, New York, NY, USA.

Nguyen, D.D., Ngo, H.H., Kim, S.D., Yoon, Y.S., 2014a. A specific pilot-scale membrane hybrid treatment system for municipal wastewater treatment. Bioresour.Technol. 169 (0), 5261.

Nguyen, D.D., Ngo, H.H., Yoon, Y.S., 2014b. A new hybrid treatment systemof bioreactors and electrocoagulation for superior removal of organic andnutrient pollutants from municipal wastewater. Bioresour. Technol. 153 (0),116-125.

Phan, H.V., Hai, F.I., Kang, J., Dam, H.K., Zhang, R., Price, W.E., Broeckmann, A.,Nghiem, L.D., 2014. Simultaneous nitrification/denitrification and trace organic contaminant (TrOC) removal by an anoxic-aerobic membrane bioreactor (MBR).Bioresour. Technol. 165, 96104.

Pilli, S., Bhunia, P., Yan, S., LeBlanc, R., Tyagi, R., Surampalli, R., 2011. Ultrasonic pretreatment of sludge: a review. Ultrason. Sonochem. 18 (1), 1-18.

Razmjoo, N., Sefidari, H., 2011. Thermal treatment of sludge. In: School of Engineering. University of Borås, Sweden, pp. 28, Master Thesis.Semblante,

G.U., Hai, F.I., Ngo, H.H., Guo, W., You, S.J., Price, W.E., Nghiem, L.D.,2014. Sludge cycling between aerobic, anoxic and anaerobic regimes to reducesludge production during 
wastewater treatment: performance, mechanisms, and implications. Bioresour. Technol. 155c, 395-409.

Tarjányi-Szikora, S., Oláh, J., Makó, M., Palkó, G., Barkács, K., Záray, G., 2013. Comparison of different granular solids as biofilm carriers. Microchem. J. 107 (0),101-107

.Wang, L.K., Shammas, N.K., Hung, Y.-T., 2009. Handbook of Environmental Engineering: Advanced Biological Treatment Processes, vol. 9. Humana Press, New York,NY, pp. 10013. 